\title{
BLISSVOX - Voice Output Communication System for Teaching, Rehabilitation, and Communication
}

\author{
G. Olaszy ${ }^{1}$, S.L. Kálmán², P. Olaszi ${ }^{3}$
}

${ }^{1}$ Phonetics Laboratory of the Linguistics Institute, 1250 Budapest Pf. 19., Hungary

${ }^{2}$ Helping Communication Methodological Centre, 1071 Budapest, Damjanich u. 28/b, fszt. 7/a, Hungary

${ }^{3}$ Technical University of Budapest, Dept. of Telecommunications and Telematics, 111 Budapest Sztoczek u. 2., Hungary

\begin{abstract}
Combining the text-to-speech system MULTIVOX and Blissymbolics and adapting them to the special needs of disabled children, outlined by the Hungarian Bliss Foundation, a speaking communication program using Bliss symbols has been developed for DOS environment. The special characteristics of this program and the preliminary results of its use will be described.
\end{abstract}

\section{Introduction}

It is well documented in the literature (see references) that, because of the type of the damage in the central nervous system, certain members of the severely speech impaired population are not able to acquire sufficient literacy skills. It is also proven that despite of this handicap, they can become,effective communicators by use of other means, like different graphic or symbol systems (e.g. Picture Communication Symbols /PCS/, Oakland Schools Picture Dictionary, PICSYMS Pictures Symbols, Pictogram Ideogram Communication /PIC/, Makaton Dictionary, etc.). One of these non-verbal, graphic systems is Blissymbolics, originally developed by Charles K. Bliss in 1949, and further developed to become an international communication system for the multiply handicapped non-verbal population by Blissymbolics Communication International (BCI) Toronto from 1971.

Present computer techniques provide the opportunity to become effective partners in communication for physically severely handicapped persons, who can be taught the use of Blissymbolics. As everywhere else in the world, most of them suffered cerebral palsy at the time of birth, and for a few of them there is no explanation for their condition.

Bliss symbols used in the BLISSVOX program were provided by the Hungarian Bliss Foundation. The Hungarian translation (Kálmán, Kassai, 1987) was based on the original vocabulary (Hehner, 1980), and the supplemented version (Reich et al., 1993). The translation was made possible by the translation agreement signed by the BCI. 
The aim of this new program was to create a tool for educational and communication purposes for non-verbal students and their teachers. At present this is the only computer program in Hungary using Blissymbolics and a speech synthesiser for communication.

\section{The basic design concepts of the BLISSVOX program}

1. The program had to be made accessible either through two external parallel switches (for the disabled user), or from the keyboard (for the teacher).

2. The graphical organisation of the screen had to be simple and informative.

3. It was an important point that assembling messages using the Bliss symbols had to be simple and easy to understand for the handicapped users.

4. In order to provide a clearly understandable picture, there could not be more than twelve Bliss symbols on the screen to choose from at one time. The meaning of each symbol is displayed right above the symbol.

5. A highlighted frame indicates the selectable symbol. In User Mode the frame moves automatically, in Teacher Mode the frame can be moved using the cursor keys.

6. In order to accommodate the motor abilities of the user, the timing between two steps of the highlighted frame can be adjusted and readjusted easily at any time.

7. The Message Field contains the selected symbols. This will be the "text" of the communication.

8. The collected message must be saved automatically under the name of the user.

9. In order to provide opportunities for special exercises, it is possible to define special groups of Bliss symbols, and to create separate files for them.

10. The user had to be able to understand the symbols themselves, the use of the program, the meaning of communication, and must be able to handle two adapted switches.

11. The speech output is performed in Hungarian.

\section{The BLISSVOX program}

\section{The following files constitute the BLISSVOX system:}

The main program BLISS.EXE

The configuration file: BLISS.CNF

The picture files containing 2500 Bliss symbols (Copyright: C.K. Bliss 1949. BLISSIMBOLICS INTERNATIONAL exclusive licence, 1982.)

The text files containing the 2500 textual definition of the Bliss symbols

Page files with .PAG extension

Data files with .MSG extension

Multivox Text-To-Speech program for Hungarian

After starting the main program the screen shows three main parts (Figure 1.): the greatest part is engaged with the 12 actual symbols (this is called a "page"). The 
bottom part of the screen contains the message field with sufficient space for displaying eight symbols. The right part of the screen accommodates the command fields, where simple pictures are used to indicate the command (Töröl 'Delete the last selected symbol', Új sor 'Begin a new message', Lap fel 'One page up', Lapok fel 'Ten pages up', Lap le 'One page down', Lapok le 'Ten pages down', Kimond 'Say message', Nyomtat 'Print'). Under the Command Field the actual page number is shown. In the status row there is help information for the teacher. A highlighted square moves through the screen continuously, step by step. The time duration between the steps can be adjusted between 1-10 seconds according to the user's needs and abilities. Only the actually highlighted symbol can be selected for building the message. After selection, the symbol appears in the Message Field (at the bottom part of the screen). The messages can be of any length. At one time the last eight pictures of the message can be seen in the Message Field. After completion of the message, it can be pronounced by selecting the 'Say' command. In the meantime the message will also be saved.

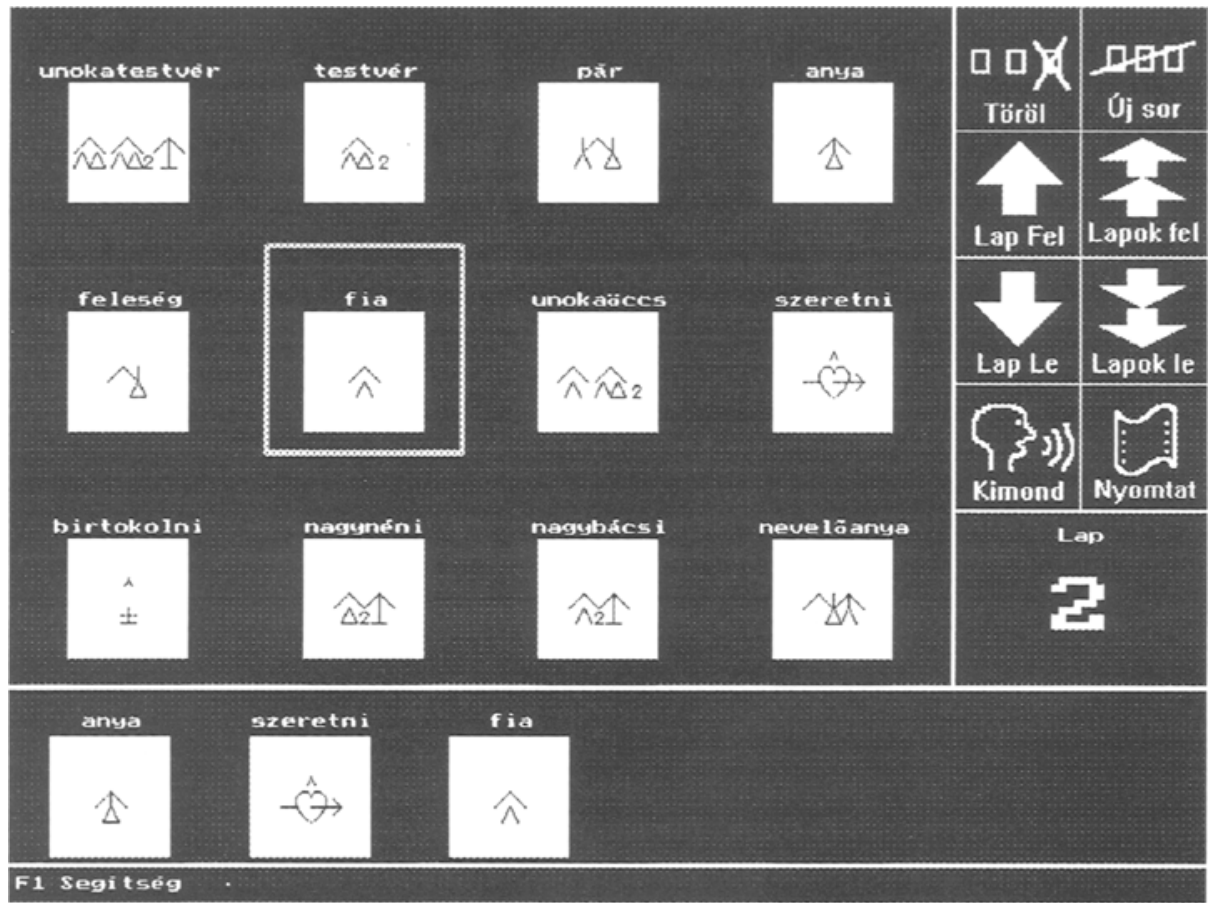

Figure 1. The main screen of the BLISSVOX program, User's Mode

\section{The configuration file BLISS.CNF}

In this file two starting parameters can be determined for the BLISS.EXE program: the default time duration between two steps and the .PAG file which will be used as a starting picture file. 


\section{The picture files}

Ready-made (originally in English) picture files containing 2500 Bliss symbols (one file each in $64 \times 64$ pixel, PCX format) and a text file containing the textual meanings of the pictures were handed though $\mathrm{BCr}$ by $\mathrm{Mr}$ Henry Russel to the Hungarian Bliss Association for the purpose of using them in this development. Each picture file is identified by its

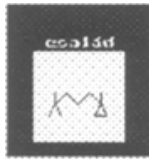
name (maximum 8 characters). In most cases this name is identical with the meaning of the text file, i.e. the textual definition in the appropriate text file. For example, picture files beginning with the letter " $\mathrm{f}$ " are:

face.pcx, factory.pcx, falafel.pcx, fallto.pcx, family.pcx, etc.

The original English text files are in alphabetic order. The construction of one textual description of a Bliss symbol (after adaptation into Hungarian) is as follows:

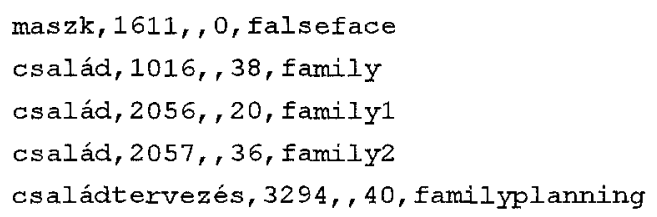

The elements of every row are separated by commas. The meaning of the elements are as follows:

Hungarian meaning, Bliss symbol serial number, Reference to the main meaning (in case of synonyms), Width of the drawing in the picture, Picture file name (without the PCX extension)

Note: If the picture file name is longer than eight letters, (e.g. "familyplanning"), the superfluous characters will be truncated in the picture file name (result: "FAMILYPL. PCX").

The adaptation of the material into Hungarian meant that in the Hungarian version we had to replace the original English meanings with the corresponding Hungarian ones based on the Hungarian Bliss Symbol Dictionary.

\section{The page files with .PAG extension}

These files serve for teaching special topics, exercises etc.

The teacher can define symbols (using their serial numbers) in a file (with .PAG extension) from the vocabulary of 2500 symbols, she/he wants to choose for a special lesson or exercise. As an example the CSALAD.PAG file can contains the following pictures about the topic "family": 
Család

$200,1134,1092,1012,1013,1014,1015,1016,1017,1018,1019,1020$

$1021,1022,1024,1025,1026,1027,1028,1029,1030,1031,1032,1033$

When choosing the CSALAD.PAG file the program will handle only these 24 pictures (two picture page with 12 symbols each), so there will be only two picture pages for the disposal of the user. Using this service of the program many .PAG files can be created and used in teaching and rehabilitation. Figure 2 . shows an example of four page files: 'All Bliss symbols', 'Letters', 'To feel', 'Family'. The arrow points at the recently chosen file to be used.

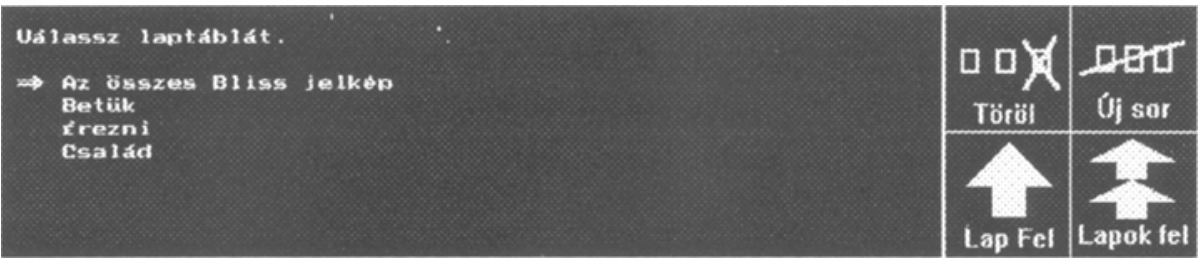

Figure 2. Selecting a Page file

\section{'The message files with .MSG extension}

The messages will be automatically saved (under the name of the actual user) when the user indicates that he/she wants to begin to construct a new message. The saved messages (i.e. the numbers of the symbols and the accompanying words) can be recalled to the screen in case of need. Thus the teacher can compare present and earlier works of his/her student. Figure 3. shows the names of four users, who already used the system, and constructed different messages. The arrow points at Rita, the chosen pupil, the earlier assembled messages of whom the teacher selected to be seen.

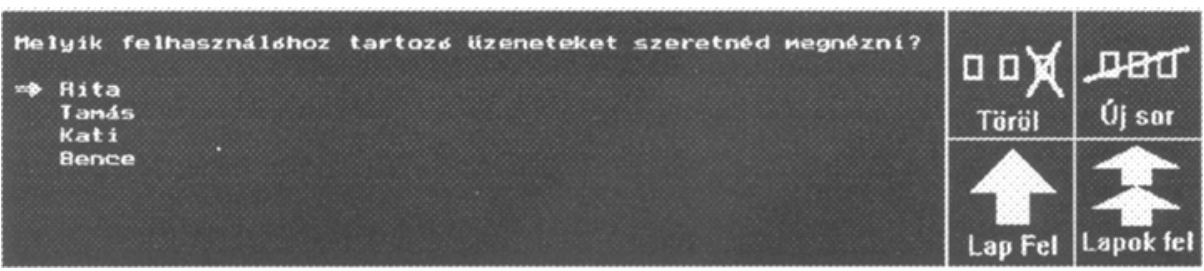

Figure 3. Selecting the messages of a user 


\section{Using the BLISSVOX program}

The program can be used in two different modes: Teacher's and User's Mode. The teacher can use the keyboard to control the program. Two main function keys are used for this work:

Enter selects picture or command (either in Teacher's Mode or User's Mode).

Tab button is used (either in Teacher's or User's Mode) for switching between the Command Field and Page Field.

A time sharing use for teachers can be performed by using the cursor buttons. For every strike the highlighted square will move further. The teacher can navigate the highlighted square on the full screen, i.e. to go through the 12 pictures (or the commands) quickly not waiting for the automatic step of the highlighted square.

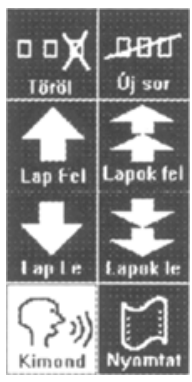

F3 recalls the list of the former written .PAG files. By using the cursor, the desired file can be actualised by pressing Enter. Now the program works with this selected .PAG file.

F4 provides opportunity to overview the formerly written messages. After selecting the desired message and pressing Enter, the content of this message will appear in the Message Field. (Figure 4.) One can either listen to the messages by using the 'Say' command, or the student can go on to add further symbols to this message.

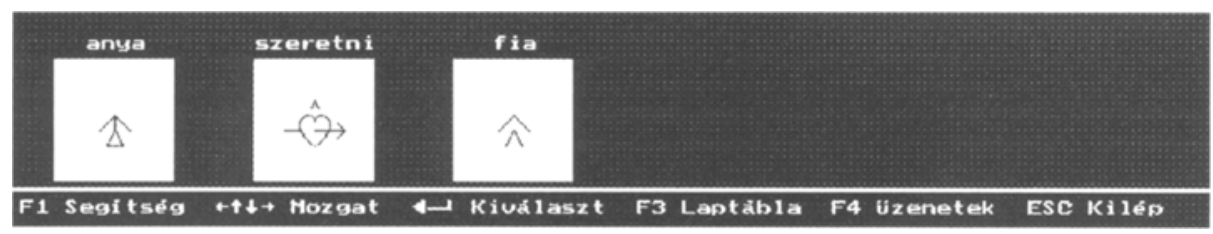

Figure 4. A message recalled by the teacher

When working on the user's level, only the two external switches are activated. Switch 1 selects the appropriate (highlighted) symbol or command (same as Enter) Switch 2 changes between the symbol field and the command field (same as Tab)

\section{Preliminary experiences with BLISSVOX}

Since we had only a very short time for experimenting with the BLISSVOX, we can hardly talk about its real everyday use. In Hungary the use of computers in communication and generally in the handicapped's care, is not a routine. It means that first we had to convince the principal of the first user's school to participate in the program at all. It was important to consult the school about the purchase of the 
necessary equipment, to train the teaching personnel, to provide continuous consultation for the teachers and the students as well. The inexperienced teachers had many problems with the use of the computer itself, and were somewhat reluctant to include this special form of communication into their daily programs.

At this moment there is one 17 year old student, whose development looks promising. He has $\mathrm{CP}$, he is athetotic, he has a serious speech impairment, but a remarkably good intellect. He is using about 800 Bliss symbols for communication, but has troubles with accessing the communication board. Considering his efficient use of the symbols, his good receptive language abilities, his already existing communication skills, he seemed a very good candidate for trying the BLISSVOX. Two different tasks were undertaken simultaneously. A trained teacher was working with him and with his personal assistant, to teach them the actual use of the computer, the handling of the switches, and other basic steps. Meanwhile work was being done to correct the small grammatical errors of the text, and the user's original vocabulary was turned into screen pages containing 12 symbols each. This latest step was a very slow and difficult job, because every symbol had to be chosen by its number, and compiled in a page. The new pages had to resemble partly the original Blissboard, but at the same time they had to be thematically sensible. (E.g. if we simply divide the original big Blissboard into 15 equal screen pages, a screen page can consist of numbers, letters, symbols for foods, clothing, and different activities etc. This way every screen would be a mixture of different topics. It is much better if a screen has a thematic approach, and there are screens with food or school items, clothing, moving, health care, feelings etc.) At this point it seems that the compilation of the individual vocabularies, which the users can choose their messages from, is the most crucial and time consuming part of the program. On the emotional level, our student already appreciates the ease which he can operate the program with, and despite of his/her restricted motor abilities, he/she can put together long and intelligent messages.

\section{Further development plans}

1. We intend to widen the program with a letter-to-text option. This means that the user will be free to create words letter by letter. The program will form words from the letters, so the synthesiser will pronounce correct words. So any kind of words, texts, and sentences can be created by the user and pronounced by the synthesiser.

2. A printing option is also planned to be added to give the teacher the possibility of printing the results of the work of the user.

3. A portable version of this system (based on notebook) will be designed for wheel chair users.

4. Adaptation for other European languages is possible, since Multivox speaks Italian, Spanish, German, Dutch, etc. The only thing to do is to translate the textual definition of the Bliss symbols to the given language. 


\section{References}

G. Olaszy, G. Gordos, G. Németh: The MULTIVOX multilingual text-to-speech converter. In Talking Machines: Theories, Models and Designs, Ed.: G. Bailly, C. Benoit and T.R. Sawallis, Elsevier Science Publishers, B.V., Amsterdam, 1992.

Beukelman, D., Yorkston, K., Dowden, P.: Communication Augmentation: A casebook of clinical management, College Hill Press, San Diego, CA, 1985

Blackstone, S.W. /Ed./: Augmentative Communication: An Introduction, ASHA, Rockville, 1986.

Blackstone, S.W.: Thinking a little harder about communication displays, Augmentative Communication News, VI/1. 1. 1993.

Burkhart, Linda J.: Total augmentative communication in the early childhood classroom, Simplified Technology, Eldersburg, MD., 1993.

Hehner, B.: Bliss symbols for Use, Blissymbolics Communication Institute, Toronto, 1980.

Kálmán, S.L.: Kommunikáció Bliss - nyelven, (Communication by Blissymbolics), Bliss Alapitvány - Origopress, Budapest, 1989.

Kálmán, S.L.: A Bliss-nyelv bevezetése, oktatásának és alkalmazásának eddigi eredményei Magyarországon, (Introduction of Blissymbolics in Hungary), Kandidátusi értekezés, Budapest, 1989.

Kálmán, S.L., Kassai, I.: Bliss-jelképszótár, (Dictionary of Bliss symbols) Másokat Segítô GT - Táltos Kiadó, Budapest, 1987.

McNaughton, Sh.: Communicating with Blissymbolics, Blissymbolics Communication Institute, Toronto, 1985.

McNaughton, Sh.: Blissymbolic and Technology, Easter Seal Communication Institute, Toronto, 1989

Reich, P., Storr, J., Woods, C.: Bliss Reference Guide, Blissymbolics Communication International, Toronto, 1993.

Schiefelbusch, R.L. /Ed./: Nonspeech language and communication: Analysis and intervention, University Park Press, Baltimore, 1980.

Vanderheiden, G.C., Grilley, K.: Non-vocal Communication Techniques for the Severely Physically Handicapped, University Park Press, Baltimore, 1976. 